\title{
Ultrasonography as a better diagnostic efficiency in rib fracture
}

\author{
Metin Uzun a, Burak Beksaça, Adnan Kara ${ }^{\mathrm{b}}$, Fatih Küçükdurmaz ${ }^{\mathrm{c}}$, Bahar Anayurdu Kırcalı ${ }^{\mathrm{d}}$, Cihangir Tetik \\ ${ }^{a}$ Department of Orthopaedics, Acıbadem Maslak Hospital, İstanbul, Turkey \\ ${ }^{b}$ Department of Orthopaedics, Şişli Etfal Training and Education Hospital, Istanbul, Turkey \\ ${ }^{c}$ Department of Orthopaedics, Medical Faculty, Bezmialem Vaklf University, İstanbul, Turkey \\ ${ }^{d}$ Department of Radiology, Aclbadem Maslak Hospital, Istanbul, Turkey
}

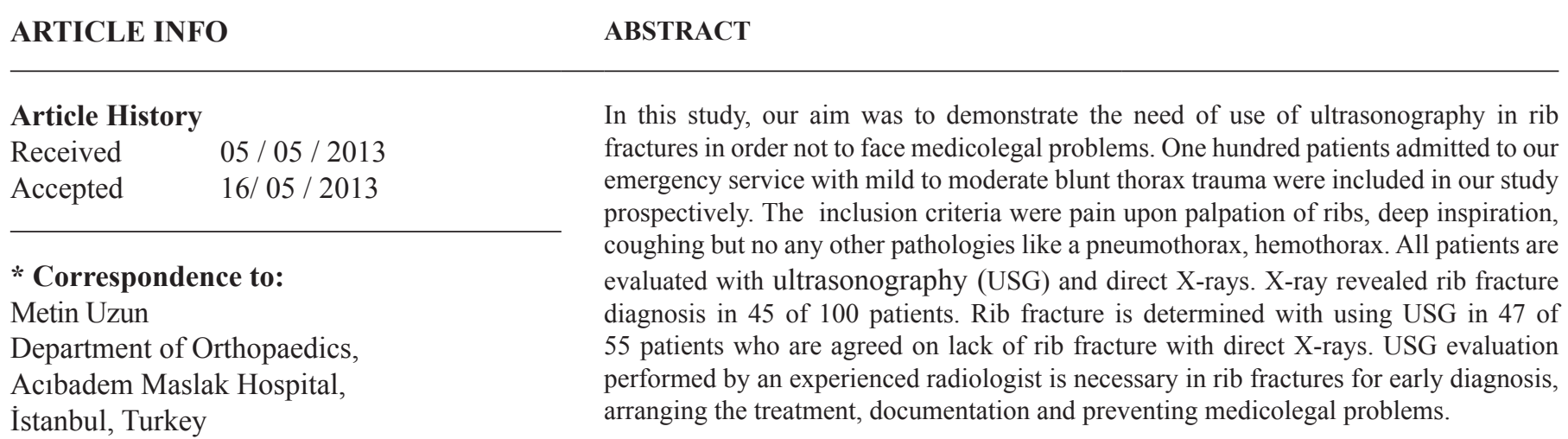

e-mail: drmetinuzun@gmail.com

\section{Keywords:}

Diagnosis

Fracture

Rib

(C) 2013 OMU

Ultrasonography

\section{Introduction}

The most frequently seen injury in patients admitted to outpatient clinics and emergency departments with blunt thoracic trauma is rib fractures (De Maseneer et al., 2004; Hurley et al., 2004). Antero-posterior (AP) and oblique direct X-rays are mostly used in diagnosis (Dubinsky and Low, 1997; Bansidhar et al., 2002 ). Non-displaced rib fractures may be frequently missed with using only direct radiograpy for diagnosis (Bansidhar et al., 2002; Bhavnagri and Mohammed, 2009; Turk et al., 2010).

Although there is no difference in treatment when there is an additional nondisplaced rib fracture due to a blunt trauma, the diagnosis of fracture may be important considering medicolegal issues. The patients admitted to emergency services with blunt thoracic trauma and have alleviating pain with palpation of ribs, deep inspiration, coughing but without additional pathologies (pneumothorax (px), hemothorax (hx)) should be evaluated with additional radiological methods (Kara et al., 2003; Hurley et al., 2004).
Many studies have shown the sensitivity of ultrasonography (USG) in rib fractures in the literature (Kara et al., 2003; Hurley et al., 2004, Turk et al., 2010). In this study, our aim was to demonstrate the need of use of USG in rib fractures in order not to face with medicolegal problems.

\section{Materials and methods}

One hundred patients ( 73 male, 27 female) admitted to our emergency service with mild to moderate blunt thoracic trauma were included in our study prospectively. The average age was 28 years (range 15 to 40 ). The inclusion criteria were pain upon palpation of ribs, deep inspiration, coughing but no any other pathologies (px, hx). All patients are evaluated with USG and direct X-rays (Fig. 1, 2). X-rays were evaluated by two traumatology and one radiology specialist before and after the USG. The patients with penetrating or major thorax trauma were excluded from the study. The patients are evaluated approximately on the fifth day (2-14 days) after the trauma. 


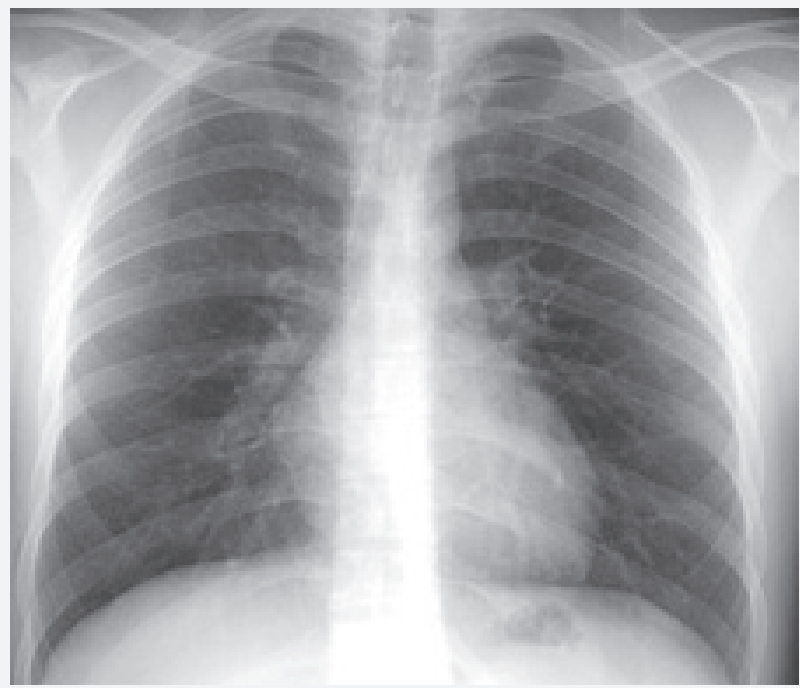

Fig. 1. Thorax AP radiography in patient with suspected rib fracture

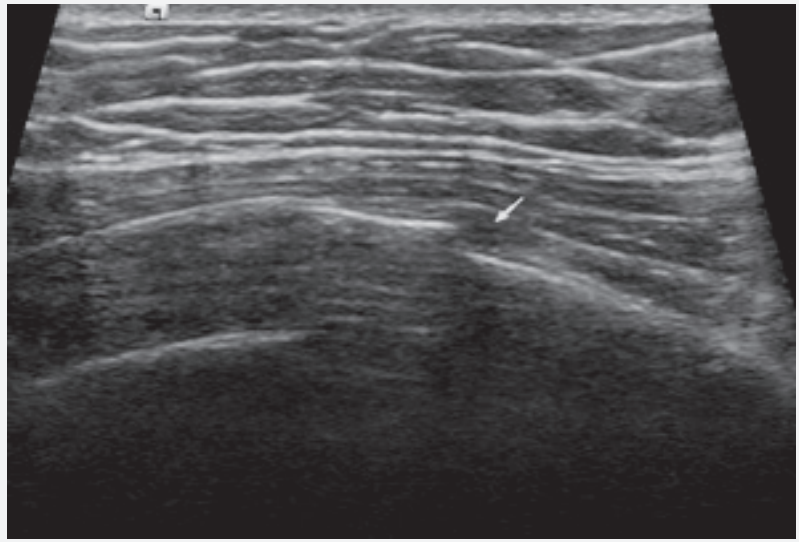

Fig. 2. The same case's ultrasound

\section{Results}

Three physicians agreed about the diagnosis of rib fracture at 20 of 100 patients with using X-ray. Only the radiologist diagnosed a rib fracture in twenty-five of remaining 80 patients at X-rays. Rib fracture is determined by using USG in 47 of 55 patients who are agreed on lack of rib fracture with direct $\mathrm{X}$-rays. As a result 92 of 100 patients with alleviating pain in palpation of ribs, deep inspiration, coughing but without any other pathologies had rib fracture.

\section{Discussion}

The most common etiological cause of rib fracture are penetrating and blunt thoracic trauma (Bhavnagri and Mohammed, 2009). The causes of trauma are usually traffic accidents, cardiopulmonary resuscitation, sports injuries, fight, and physical abuse (Bhavnagri and Mohammed, 2009). Rib fractures following major blunt or penetrating trauma may be seen with complication as a px, hx. The patients included in our study were injured with minor blunt during sports activities and there were no other comorbidities.

Although, AP chest radiography are frequently used in diagnosis of rib fracture following thoracic trauma (Bansidhar et al., 2002; Bhavnagri and Mohammed, 2009; Turk et al., 2010). Dubinsky demostrated $50 \%$ of misdiagnosis (false negative) of rib fractures with using only radiography (Dubinsky and Low, 1997). Hence oblique chest radiography started to use for prevention of misdiagnosis, Lamb showed that changing the orientation of the thoracic radiograph degree can change the misdiagnosis rate (Lamb et al., 2011).

Lamb et al. (2011) reported that diagnosis of exact rib fracture may be important due to documentation, pain management, exact number of fractures.

Documentation is important for medicolegal issues and non-steroidal anti inflammatory drugs (NSAID) are usually enough for soft tissue trauma, on the other hand narcotics or intercostal nerve block may be necessary for pain management in rib fractures (Dubinsky and Low, 1997). Stawicki et al. (2004) and Holcomb et al. (2003) reported determining the number of fractured ribs may be important because of increased risk of death in the presence of more than four rib fractures in patients older than 45 years. Knowing the exact number of fractured ribs may be useful to predict additional injuries; the most commonly fractured ribs were $4^{\text {th }}$ to 10 th. ribs. Abdominal visceral injuries may accompany when there is fracture at $10^{\text {th }}$ to $12^{\text {th }}$ ribs (Bansidhar et al., 2002; Kara et al., 2003).

This study is conducted to evaluate the effectiveness of USG in the diagnosis of rib fractures, compared to direct radiography which is shown to have misdiagnosing rates up to $50 \%$.

AP thorax or $45^{\circ}$ oblique X-rays are used for rib trauma and show that misdiagnosis (false negative) of rib fractures with a rate of $45 \%$ (Dubinsky and Low, 1997).

Our results are compatible with Dubinsky (Dubinsky and Low, 1997). So that, we need a better investigation method than X-ray.

The use of USG for fracture diagnosis was first described by Davidson and Markowitz in children's elbow and forearm fractures (Davidson et al., 1994; Markowitz et al., 1992). They described the advantage of ultrasound to avoid the ionizing radiation of fluoroscopy and revealing the cartilage and unossified bone structure. Using of USG for bone fractures; Mathis described that thorax ultrasonography technique for bone fractures suspecions (Mathis, 1997). With the use this technique; Hurley et al., (2004), Turk et al., (2010), Chan et al. (2009) emphasized the importance of USG in the diagnosis of rib fractures comparing to direct radiographs and published excellent results. These results revealed that widely using of sonography at the emergency department; in spide of bedside USG has been descriped as a visual stethoscope (Chan, 2009;) USG is not in routine use in suspected rib fractures although it is avoiding the ionizing radiation, easily available, cheap, simple radiologic modality (Bhavnagri and Mohammed, 2009).

There are two limitations for applying USG for rib trauma. First one is retroscapular and infraclavicular portion of the rib are inaccessible. Second one may be time consuming. Hurley and Griffith reported 10 to 15 minutes (Hurley et al., 2004; Griffith et al., 1999). This required time would not be very significant when compared with the waiting time for chest radiography in a busy department. Chan experience and opinion, a clinician is likely to be able complate the USG protocol in less time than radiologist (Chan, 2009).

Another radiologic examination used in diagnosis of rib fractures is computed tomography (CT). CT is a gold stan- 
dart for multitrauma, major and complicated thorax injury (Trupka, 1997; Traub et al., 2007). Trupka et al, Traub et al. demonstrated the benefit of CT when rib $\mathrm{fx}$ is accompanied by other thorax injuries such as hemothorax, pneumothorax.

Although this advantage of CT, exposure to radiation and its cost are its major disadvantages. Malghem et al. (2001) reported that costal cartilage fracture detection with USG was better than CT. CT is used for major blunt and penetrating thorax injuries in our clinic.

Niitsu and Takeda (2003) demonstrated the increased sensitivity of scintigrafy in rib fractures. Presence of radioactivity and long duration of obtaining is disadvantages. Sintigraphy is not a routine examination in trauma cases but used in pathologic fractures. The relability of diagnosis depends on the experience of radiologist who evaluate X-Ray, CT, scintigraphy and USG. Lamb et al. (2011) demonstrated the specificity of the radiologists comparing to clinician in the diagnosis of rib fractures with using X-Rays. In our study, radiologists diagnosed $72(72 \%)$ rib fractures who are missed by other specialists. Radiologists use high resolution programs in evaluation of X-rays which may be a factor in their reliability in addition to their experience of evaluating X-Rays.

As a results, a USG evaluation performed by an experienced radiologist is necessary in rib fractures to arrange the treatment, documentation and to prevent medicolegal problems.

\section{REFERENCES}

Bansidhar, B.J., Lagares-garcia, J.A., Miller, S.L., 2002. Clinical rib fractures: Are follow-up chest x-rays a waste of resources? Am. Surg. 68, 449-453.

Bhavnagri, S.J., Mohammed, T.L., 2009. When and how to image suspected broken rib. Cleve Clin. J. Med. 76, 309-314. doi: 10.3949/ ccjm.76a.08026

Chan, S.S., 2009. Emergency bedside ultrasound for the diagnosis of rib fractures. Am. J. Emerg. Med. 27, 617-620.

Davidson, R.S., Markowitz, R.I., Domans, J., Drummond, D.S., 1994. Ultrasonographic evalution of the elbow in infants and young children after suspected trauma. J. Bone Joint. Surg. Am. 76, 1804-1813.

De Maseneer, M., De Mey, J., Lenchik, L., Everaert, H., Osteaux, M., 2004. Helical CT of Rib Lesions: A Pattern-Based Approach. Am. J. Roentgenol. 182, 173-179.

Dubinsky, I., Low, A., 1997. Non-life threatening blunt chest trauma: Appropriate investigation and treatment. Am. J. Emerg. Med. 15, $240-243$.

Griffith, J.F., Rainer, T.H., Ching, A.S.C., Law, K.L., Cocks, R.A., Metreweli, C., 1999. Sonography compared with radiography in revealing acute rib fracture. Am. J. Roentgenol. 173, 1603-1609.

Holcomb, J.B., McMullin, N.R., Kozar, R.A., Lygas, M.H., Moore, F.A., 2003. Morbidity from rib fractures increases after age 45. J. Am. Coll. Surg. 96, 549-555.

Hurley, M.E., Keye, G.D., Hamilton, S., 2004. Is ultrasound really helpful in the detection of rib fractures? Injury.35, 562-566.

Kara, M., Dikmen, E., Erdal, H.H., Simsir, I., Kara, S.A., 2003. Disclosure of unnoticed rib fractures with the use of ultrasonogtaphy in minor blunt chest trauma. Eur. J. Cardiothorac. Surg. 24, 608-613.

Lamb, C.R., Parry, A.T., Baines, E.A., Chang, Y.M., 2011. Does changing the orientation of a thoracic radiograph aid diagnosis of rib fractures? Vet. Radiol. Ultrasound. 52, 75-78.

Malghem, J., Vande Berg, B., Lecouvet, F., Maldague, B., 2001. Costal cartilage fractures as revealed on CT and sonog-raphy. AJR Am J Roentgenol. 176, 429-432.

Markowitz, R.I., Davidson, R.S., Harty, M.P., Bellah, R.D., Hubbard, A.M., Rosenberg, H.K., 1992. Sonography of the elbow in infants and children. Am. J. Roentgenol. 159, 829-833.

Mathis, G., 1997. Thoraxsonography-Part 1: Chest wall and pleura. Ultrasound. Med. Biol. 23, 1131-1139.

Niitsu, M., Takeda, T., 2003. Solitary hot spots in the ribs on bone scan: Value of thin-section reformatted computed tomography to exclude radiography-negative fractures. J. Comput. Assist. Tomogr. 27, 469-474.

Stawicki, S.P., Grossman, M.D., Hoey, B.A., Miller, D.L., Reed, J.F. 3rd., 2004. Rib fractures in the elderly: A marker of injury severity. J. Am. Geriatr. Soc. 52, 805-808.

Traub, M., Stevenson, M, McEvoy, S., Briggs, G., Lo, S.K., Leibman, S., Joseph, T., 2007. The use of chest computed tomography versus chest $\mathrm{X}$-ray in patients with major blunt trauma. Injury. 38, 43-47.

Trupka, A., Waydhas, C., Hallfeldt, K.K., Nast-Kolb, D., Pfeifer, K.J., Schweiberer, L., 1997. Value of thoracic computed tomography in the first assessment of severely injured patients with blunt chest trauma: Results of a prospective study. J. Trauma. 43, 405-412.

Turk, F., Kurt, A.B., Sağlam, S., 2010. Evaluation by ultrasound of traumatic rib fractures missed by radiography. Emerg. Radiol. 17, $473-477$. 